\title{
Nutritional status, tooth wear and quality of life in Brazilian schoolchildren
}

\author{
Francisco Juliherme Pires de Andrade ${ }^{1}$, André de Carvalho Sales-Peres ${ }^{2}$, \\ Patricia Garcia de Moura-Grec ${ }^{1}$, Marta Artemisa Abel Mapengo', \\ Arsenio Sales-Peres ${ }^{1}$ and Sílvia Helena de Carvalho Sales-Peres ${ }^{1, *}$ \\ 'Department of Pediatric Dentistry, Orthodontics and Public Health, Bauru School of Dentistry, University of São \\ Paulo, Avenue Octávio Pinheiro Brisolla 9-75, Bauru, SP, Brazil: ${ }^{2}$ Catanduva School of Medicine, Integrated \\ Colleges Priest Albino, Catanduva, SP, Brazil
}

Submitted 31 March 2015: Final revision received 30 July 2015: Accepted 28 August 2015: First published online 30 September 2015

\begin{abstract}
Objective: To evaluate the correlation among nutritional status, tooth wear and quality of life in Brazilian schoolchildren.

Design: The study followed a cross-sectional design. Nutritional status was measured via anthropometry using BMI and tooth wear was measured using the Dental Wear Index; both these assessments were carried out by a trained recorder according to standard criteria. A modified version of the Child Oral Impacts on Daily Performances was used to assess quality of life.

Setting: City of Bauru, in Brazil.

Subjects: A cluster sample of 396 schoolchildren (194 boys and 202 girls) aged 7-10 years.

Results: The anthropometric assessment showed similar situations for both sexes regarding underweight (31.40\% in boys and 30.20\% in girls) and overweight/ obesity (33.96\% in boys and $33.17 \%$ in girls). The underweight children showed a greater severity of tooth wear in the primary teeth $(\mathrm{OR}=0.72$; CI $0.36,1.42)$, although in the permanent dentition the obese children had a greater severity of tooth wear $(\mathrm{OR}=1 \cdot 42 ; 95 \% \mathrm{CI} 0 \cdot 31,6 \cdot 55)$. The tooth wear was correlated with age for both dentitions.

Conclusions: Tooth wear in the primary and permanent dentition may be related to nutritional status. Tooth wear and obesity did not have a significant impact on the schoolchildren's perception of quality of life.
\end{abstract}

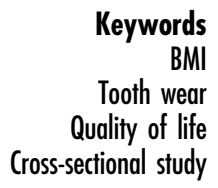

Up until the last century, chronic undernutrition was one of the most important public health concerns around the world. Within recent decades, obesity has emerged as a new issue of similar global importance. These nutritional extremes persist alongside each other in many countries and populations ${ }^{(1-3)}$. Brazil is undergoing a period of important epidemiological transition that has been associated with both demographic and nutritional changes. This transition has resulted in a reduction in the prevalence of underweight, with a subsequent increase in the prevalence of obesity ${ }^{(4,5)}$.

Environmental factors ${ }^{(6)}$ such as a child's nutritional status ${ }^{(7)}$ may also influence the occurrence of oral health problems ${ }^{(8)}$. Tooth wear is a progressive physiological condition that affects the dentition throughout life. The tooth wear may become pathological as a result of three processes, erosion, abrasion and attrition ${ }^{(9-11)}$, that occur simultaneously in the oral cavity $^{(12,13)}$. It has been recognized that tooth wear is a clinical problem that is becoming increasingly important in the population $^{(12,14,15)}$. Thus, tooth wear can compromise the health of the teeth individually or the entire dentition, with manifestations ranging from severe loss of tooth structure to dentin hypersensitivity, abnormal occlusion and aesthetic damage ${ }^{(9-11,16)}$.

Oral health problems may have an impact on quality of life, since the concept of health is complete physical, mental and social well-being and not merely the absence of disease or infirmity. Therefore, the analysis of quality of life is essential for understanding the true impact of dental disease, especially in children. The outcome could be useful in planning public health policies for prioritization of care and evaluating outcomes from treatment strategies and initiatives ${ }^{(17,18)}$.

Tooth wear as well as dental caries are diseases of multifactorial aetiology. Factors like frequent contact 
of gastric juice with teeth surfaces in patients with eating disorders and gastro-oesophageal reflux disease, special diets, regular consumption of acidic beverages, use of some medications and drugs ${ }^{(19)}$, residence in rural areas, electric tooth-brushing and snoring ${ }^{(20)}$ have been described as having an association with tooth wear. In obese/overweight patients the risk factors for tooth wear appear more frequently because harmful eating habits (with the consumption of acidic drinks in greater quantity and frequency) and possible eating disorders (bulimia, anorexia nervosa and gastro-oesophageal reflux) can cause obesity and tooth wear to share the same pathogenesis factors, predisposing the overweight or obese patient to tooth wear ${ }^{(21)}$.

However, there is a lack of information in the literature about the influence of nutritional status on tooth wear. The aim of the present study was to evaluate nutritional status, tooth wear and their impact on the quality of life of Brazilian schoolchildren.

\section{Methods}

The study design was cross-sectional, involving children of both sexes, aged 7-10 years, who were enrolled in public schools.

\section{Ethical considerations}

The Research Ethics Committee of the Bauru School of Dentistry of the University of São Paulo approved the study. Positive consent was obtained from the participants' legal guardians on the day of the clinical examination and conducted in full accordance with the World Medical Association Declaration of Helsinki.

\section{Sample structure}

The representative sample was composed of 7-10year-old schoolchildren from Bauru, a city in the state of São Paulo, south-east Brazil. Bauru has a fluoridated water supply (0.7 ppm) and an estimated population of 343937 , including 6700 children regularly attending sixteen public schools ${ }^{(22)}$. For the sample size calculation, the following parameters were used: prevalence of tooth wear of $30 \%$, SE of $5 \%, 95 \% \mathrm{CI}$, design effect of $1 \cdot 4$, and adding $10 \%$ for losses $^{(12,21)}$. The minimum sample size required for the present study was 372 schoolchildren.

The sixteen public schools were randomized and selected in order to comprise all the regions of the city, providing a sample that represents the socio-economic condition of the whole population. The random sample was stratified by sex and age, and included a total of 396 schoolchildren (194 boys and 202 girls).

The exclusion criteria were (i) children or parents not authorizing participation in the epidemiological survey and (ii) if the children were currently wearing orthodontic appliances and had extensive dental restorations.

\section{Process calibration}

Training and calibration exercises for two examiners took place over a 6-month period prior to the main survey and involved training on cast models, photographs and subjects. The calibration process was composed of three steps: (i) examiners were trained to learn the Dental Wear Index (DWI); (ii) calculation of kappa statistics to analyse agreement and to create matrices; and (iii) examiners performed new exams and a gold standard for examiners was established to evaluate the accuracy. The intra-exam reliability showed a range of $\kappa$ values between 0.91 and $0 \cdot 87$. The inter-exam and inter-examiner reliability showed a range of $\kappa$ values between 0.88 and 0.82 .

\section{Examination methodology}

Examinations were carried out in classrooms by trained examiners under standardized conditions with the children in sitting position. The teeth were dried using equipment with an air syringe and were examined using a disposable mouth mirror and CPI probe under natural lighting. All cross-infection control measures were adopted and the clinical equipment was used in accordance with the WHO guidelines (2010) for epidemiological studies ${ }^{(23)}$.

\section{Nutritional status}

Anthropometric weight and height measures were made at the time of the exams, with the children wearing light clothing and no shoes. Height was measured using a standard physician's scale and weight was measured with a digital balance. The nutritional status of the children was evaluated by BMI $\left(\mathrm{kg} / \mathrm{m}^{2}\right)$ and classified according to the WHO (2006) reference ${ }^{(24)}$, which defines BMI percentiles for age and sex. The internationally recognized classification of BMI into underweight, normal weight, overweight and obesity was conducted with special tables from the obesity consortium for children and adolescents.

\section{Tooth wear}

To evaluate tooth wear, the DWI was used according to the diagnostic criteria proposed by Sales-Peres ${ }^{(21)}$. The DWI evaluates all teeth, which are divided into three surfaces (buccal, incisal/occlusal and lingual surfaces). The surfaces were scored as 'a' or ' 0 ' (normal), 'b' or ' 1 ' (enamel involvement), 'c' or '2' (exposed dentin), 'd' or '3' (secondary dentin or pulp exposure), 'e' or '4' (restored due to tooth wear) and '-' or '9' (could not be assessed) for the primary and permanent teeth, respectively. The buccal/facial, incisal/occusal and lingual/palatine surfaces were examined and recorded on a specific form. The DWI was developed according to decayed, missing and filled teeth. The criteria used for examinations were: 'normal' (no evidence of wear - no loss of surface features); 'incipient' (tooth wear into enamel - loss of enamel giving a smooth, glazed, shiny appearance, dentine is not involved); 'moderate' (tooth wear into dentine - extensive 
loss of enamel with dentine involvement, exposure of dentine); 'severe' (tooth wear into pulp - extensive loss of enamel and dentine with secondary dentine or pulp exposure); 'restored' (tooth wear leading to restoration tooth received restorative treatment due to tooth wear); and 'could not be assessed' (extensive caries, large restoration, fractured tooth, missing tooth, orthodontic brackets).

\section{Quality of life}

A modified version of the Child Oral Impacts on Daily Performances (Child-OIDP) was used as a measure of the oral health-related quality of life. For the application of the Child-OIDP, children were initially asked to record all problems related to oral health experienced in the past 3 months ${ }^{(25)}$ including eating, emotion, cleaning, schoolwork, speaking, social contact, smiling and sleeping. This is a composite indicator that covers basic daily life activities and the frequency of impact of oral conditions on these activities.

\section{Statistical analysis}

Data were analysed using the statistical software package IBM SPSS Statistics version 20. For all variables tested, the significance was pre-determined at $\alpha=0.05$. Data were analysed using a univariate analysis. For the relationships between an ordinal dependent variable and one or more categorical or continuous explanatory variables, logistic and linear regression was used. In addition, the odds ratios of the relationships were calculated.

\section{Results}

Overall the sample was composed of 396 children, 194 boys and 202 girls. The distribution of the 7- to 10-year-old schoolchildren in relation to the BMI revealed that $32 \cdot 79 \%$ were underweight and 34.67\% were overweight and obese. The numbers of boys and girls in the age groups of
7, 8, 9 and 10 years old were numerically equivalent (Table 1).

The distribution and univariate analysis showed that a total of 57024 dental surfaces were evaluated, with approximately 144 faces per child, and revealed greater severity of tooth wear in the occlusal (molars and premolars) and lingual/palatal surfaces (incisors). Table 2 describes a higher prevalence of tooth wear in the primary teeth of the 7- and 8-year-old children compared with the 9- and 10-year-olds who were evaluated. In the permanent teeth, there was no prevalence of tooth wear regarding the children's age.

Among the 396 children in the sample, the overweight and obese children showed moderate tooth wear on the primary dentition. Similarly data on underweight children revealed moderate tooth wear on the primary dentition. Underweight children had greater severity of tooth wear in the primary teeth $(\mathrm{OR}=0.72)$, while obese children showed greater severity of worn permanent teeth (OR $=1 \cdot 42$; Table 3).

There was an association between the number of worn primary teeth and the age $(\mathrm{OR}=0.51)$ and $\mathrm{BMI}$ $(\mathrm{OR}=0.92)$ of the children. However, for permanent teeth, an association was found only between tooth wear and children's age $(\mathrm{OR}=1 \cdot 58$; Table 4$)$.

The linear regression analysis showed that quality of life had no association with the children's age, BMI or tooth wear in the primary or permanent teeth (Table 5).

\section{Discussion}

The present study evaluated the nutritional status, tooth wear and quality of life in Brazilian schoolchildren. The data suggest an association of nutritional status with tooth wear and children's age. Quality of life showed no association with tooth wear and nutritional status.

Table 1 Distribution of nutritional status by age and sex among 7- to 10-year-old schoolchildren ( $n$ 396) from Bauru, São Paulo, Brazil

\begin{tabular}{|c|c|c|c|c|c|c|c|c|c|}
\hline & \multicolumn{9}{|c|}{ Age } \\
\hline & \multicolumn{2}{|c|}{7 years } & \multicolumn{2}{|c|}{8 years } & \multicolumn{2}{|c|}{9 years } & \multicolumn{2}{|c|}{10 years } & \multirow[b]{2}{*}{ Total $n$} \\
\hline & $n$ & $\%$ & $n$ & $\%$ & $n$ & $\%$ & $n$ & $\%$ & \\
\hline \multicolumn{10}{|l|}{ Boys } \\
\hline Underweight & 15 & 28.85 & 13 & 32.43 & 15 & 30.00 & 18 & 33.33 & 61 \\
\hline Normal weight & 20 & 38.46 & 13 & $35 \cdot 14$ & 18 & 36.00 & 20 & 37.04 & 71 \\
\hline Overweight & 4 & $7 \cdot 69$ & 6 & $16 \cdot 22$ & 8 & $16 \cdot 00$ & 7 & 12.96 & 25 \\
\hline Obesity & 13 & 25.00 & 6 & $16 \cdot 22$ & 9 & $18 \cdot 00$ & 9 & 16.67 & 37 \\
\hline Total & 52 & $100 \cdot 00$ & 38 & $100 \cdot 00$ & 50 & $100 \cdot 00$ & 54 & $100 \cdot 00$ & 194 \\
\hline \multicolumn{10}{|l|}{ Girls } \\
\hline Underweight & 5 & $11 \cdot 11$ & 15 & 32.61 & 15 & 25.45 & 26 & $47 \cdot 27$ & 61 \\
\hline Normal weight & 21 & $46 \cdot 67$ & 16 & 34.78 & 21 & 38.18 & 16 & 29.09 & 74 \\
\hline Overweight & 9 & $20 \cdot 00$ & 4 & $8 \cdot 70$ & 7 & $12 \cdot 73$ & 7 & $12 \cdot 73$ & 27 \\
\hline Obesity & 10 & $22 \cdot 22$ & 11 & 23.91 & 13 & $23 \cdot 64$ & 6 & 10.91 & 40 \\
\hline Total & 45 & $100 \cdot 00$ & 46 & $100 \cdot 00$ & 56 & $100 \cdot 00$ & 55 & $100 \cdot 00$ & 202 \\
\hline
\end{tabular}


Table 2 Distribution of severity and prevalence of tooth wear by age and dentition among 7- to 10-year-old schoolchildren ( $n$ 396) from Bauru, São Paulo, Brazil

\begin{tabular}{|c|c|c|c|c|c|c|c|c|}
\hline & \multicolumn{8}{|c|}{ Age } \\
\hline & \multicolumn{2}{|c|}{$\begin{array}{c}7 \text { years } \\
\text { (1960 dental surfaces) }\end{array}$} & \multicolumn{2}{|c|}{$\begin{array}{c}8 \text { years } \\
\text { (1660 dental surfaces) }\end{array}$} & \multicolumn{2}{|c|}{$\begin{array}{c}9 \text { years } \\
\text { (2120 dental surfaces) }\end{array}$} & \multicolumn{2}{|c|}{$\begin{array}{c}10 \text { years } \\
\text { (2180 dental surfaces) }\end{array}$} \\
\hline & $n$ & $\%$ & $n$ & $\%$ & $n$ & $\%$ & $n$ & $\%$ \\
\hline \multicolumn{9}{|c|}{ Degree of tooth wear on primary teeth } \\
\hline Normal & 789 & $40 \cdot 25$ & 785 & $47 \cdot 28$ & 1249 & 58.91 & 1649 & $75 \cdot 64$ \\
\hline Incipient & 607 & 30.97 & 358 & 21.56 & 368 & $17 \cdot 35$ & 197 & 9.03 \\
\hline Moderate & 561 & 28.63 & 516 & 31.08 & 500 & 23.58 & 331 & $15 \cdot 18$ \\
\hline Severe & 3 & 0.15 & 1 & 0.08 & 3 & 0.16 & 3 & 0.15 \\
\hline \multicolumn{9}{|l|}{ Prevalence } \\
\hline Yes & 1171 & $59 \cdot 75$ & 875 & 52.72 & 871 & 41.09 & 531 & $24 \cdot 36$ \\
\hline \multirow[t]{3}{*}{ No } & 789 & $40 \cdot 25$ & 785 & $47 \cdot 28$ & 1249 & $58 \cdot 91$ & 1649 & $75 \cdot 64$ \\
\hline & \multicolumn{2}{|c|}{$\begin{array}{c}7 \text { years } \\
\text { (2744 dental surfaces) }\end{array}$} & \multicolumn{2}{|c|}{$\begin{array}{c}8 \text { years } \\
\text { (2324 dental surfaces) }\end{array}$} & \multicolumn{2}{|c|}{$\begin{array}{c}9 \text { years } \\
\text { (2968 dental surfaces) }\end{array}$} & \multicolumn{2}{|c|}{$\begin{array}{c}10 \text { years } \\
\text { (3052 dental surfaces) }\end{array}$} \\
\hline & $n$ & $\%$ & $n$ & $\%$ & $n$ & $\%$ & $n$ & $\%$ \\
\hline \multicolumn{9}{|c|}{ Degree of tooth wear on permanent teeth } \\
\hline Normal & 2005 & 73.06 & 1653 & $71 \cdot 12$ & 2018 & 67.99 & 1824 & 59.76 \\
\hline Incipient & 178 & 6.48 & 266 & 11.44 & 394 & $13 \cdot 27$ & 722 & 23.65 \\
\hline Moderate & 2 & 0.07 & 0 & 0.00 & 0 & 0.00 & 4 & 0.13 \\
\hline Severe & 5 & $0 \cdot 18$ & 4 & $0 \cdot 17$ & 1 & 0.03 & 1 & 0.03 \\
\hline \multicolumn{9}{|l|}{ Prevalence } \\
\hline Yes & 185 & 8.45 & 270 & 14.05 & 395 & $16 \cdot 37$ & 727 & 28.50 \\
\hline No & 2005 & 91.55 & 1653 & 85.95 & 2018 & 83.63 & 1824 & 71.50 \\
\hline
\end{tabular}

Table 3 Univariate analysis of severity of tooth wear by nutritional status among 7- to 10-year-old schoolchildren $(n$ 396) from Bauru, São Paulo, Brazil

\begin{tabular}{|c|c|c|c|c|c|c|c|c|c|c|}
\hline \multirow[b]{3}{*}{ Nutritional status } & \multicolumn{5}{|c|}{ Primary teeth } & & \multicolumn{4}{|c|}{ Permanent teeth } \\
\hline & \multicolumn{2}{|c|}{ Severity of tooth wear } & \multirow[b]{2}{*}{ OR } & \multirow[b]{2}{*}{$95 \% \mathrm{Cl}$} & \multirow[b]{2}{*}{$P$} & \multicolumn{2}{|c|}{ Severity of tooth wear } & \multirow[b]{2}{*}{ OR } & \multirow[b]{2}{*}{$95 \% \mathrm{Cl}$} & \multirow[b]{2}{*}{$P$} \\
\hline & Enamel & Dentin & & & & Enamel & Dentin & & & \\
\hline Normal weight & 19 & 126 & 1.00 & Ref. & - & 141 & 4 & 1.00 & Ref. & - \\
\hline Underweight & 21 & 101 & 0.72 & $0.36,1.42$ & 0.044 & 119 & 3 & 0.88 & $0.19,4.04$ & 0.817 \\
\hline Overweight & 12 & 40 & 0.50 & $0.20,1.12$ & 0.141 & 51 & 1 & 0.69 & $0.07,6.32$ & 0.853 \\
\hline Obesity & 17 & 60 & 0.53 & $0.25,1.09$ & 0.125 & 74 & 3 & 1.42 & $0.31,6.55$ & 0.953 \\
\hline
\end{tabular}

Ref., reference category.

Table 4 Association of tooth wear in primary and permanent teeth with age and BMI among 7- to 10-year-old schoolchildren ( $n$ 396) from Bauru, São Paulo, Brazil

\begin{tabular}{|c|c|c|c|c|c|c|}
\hline & \multicolumn{3}{|c|}{ Tooth wear in primary teeth } & \multicolumn{3}{|c|}{ Tooth wear in permanent teeth } \\
\hline & $P$ & OR & $95 \% \mathrm{Cl}$ & $P$ & OR & $95 \% \mathrm{Cl}$ \\
\hline Age & $0.000^{*}$ & 0.510 & $0.387,0.671$ & $0.001^{*}$ & 1.581 & $1 \cdot 206,2 \cdot 074$ \\
\hline $\mathrm{BMI}$ & $0.028^{*}$ & 0.922 & $0.858,0.991$ & 0.672 & 0.982 & $0.905,1.067$ \\
\hline
\end{tabular}

*Significant difference $(P<0.05)$.

The use of BMI for the current epidemiological research was conducted according to the protocol of the WHO (2006) reference $^{(24)}$. For each age group there are limits that define the values for underweight, normal weight, overweight and obesity. Previous studies that analysed nutritional status in Brazilian children showed a higher prevalence of overweight (13.35\%) and obesity (8.69\%) among these children compared with underweight $(3 \cdot 18 \%)^{(26,27)}$. However, these results differ from those found in the present study. In the sample we analysed, there were similar prevalences of underweight $(32 \cdot 79 \%)$ and overweight/obese children (34.67\%). The results of studies conducted during the past three decades are indicative of an antagonism between temporal tendencies of underweight and obesity, defining one of the characteristics of the process of nutritional transition that occurs in the country ${ }^{(24,27-30)}$. 
Table 5 Multiple linear regression of age, BMI and tooth wear in primary and permanent teeth, with quality of life as the dependent variable, among 7- to 10-year-old schoolchildren ( $n$ 396) from Bauru, São Paulo, Brazil

\begin{tabular}{lccrrr}
\hline & \multicolumn{4}{c}{ Quality of life } \\
\cline { 2 - 5 } Variable & Unstandardized coefficient, $B$ & SE & Standardized coefficient, $\beta$ & $t$ & $P$ \\
\hline Age & -0.178 & 0.203 & -0.047 & -0.877 & 0.381 \\
BMI & 0.083 & 0.064 & 0.067 & 1.301 & 0.194 \\
Tooth wear in primary teeth & -0.038 & 0.358 & -0.006 & -0.106 & 0.916 \\
Tooth wear in permanent teeth & -0.691 & 0.619 & -0.057 & -1.116 & 0.265 \\
\hline
\end{tabular}

A few studies have analysed the influence of nutritional factors on the prevalence of tooth wear ${ }^{(31,32)}$; in these surveys, no significant associations were found, although our results verified that there was an influence of nutritional status on tooth wear. The DWI was designed to provide a simple scoring system that can be used with the diagnostic criteria of all existing indices, with the purpose of transferring their results to record the most severely affected surface and using the cumulative score to guide management of the condition ${ }^{(12)}$. The DWI could be a useful instrument for broad epidemiological surveys and is designed to be a simple and transferable scoring system. It covers all types of tooth wear, facilitating the evaluation in epidemiological studies ${ }^{(12)}$.

The data regarding tooth wear and nutritional status showed that underweight children had a higher severity of tooth wear in the primary dentition. Studies evaluating the salivary flow and composition in underweight children have shown that malnutrition may be one factor that might compromise salivary gland function ${ }^{(33)}$. Deficiency of specific nutrients, such as protein, minerals and vitamins, has been related to impaired salivary gland function ${ }^{(33)}$. Studies in children have shown that the severity of protein-energy malnutrition is related to the extent of reduction of stimulated salivary secretion rate. Thus the saliva has an important role in ensuring adequate protection from oral diseases, especially tooth wear ${ }^{(13,33)}$, and underweight children do not have an adequate protection factor for tooth wear, due to possible changes in the composition and flow of saliva. Tooth wear in the primary teeth is regarded as a predictor of increased risk of erosion wear and general wear in the permanent teeth $^{(34,35)}$, so precise preventive and therapeutic measures for tooth wear and control of nutritional status are necessary to avoid increasing clinical problems.

In the permanent teeth, greater severity of tooth wear was found in overweight and obese children. The change in dietary patterns and consumption of foods with erosive potential can trigger this change in overweight children. Several factors may have contributed to increase the risk of dental erosion in children and adolescents. Increased prosperity and availability of acidic products such as soft drinks, sports drinks and citrus fruit juices that have a greater marketing may all have enhanced the exposure of paediatric dentition to large amounts of acids at an ever earlier age ${ }^{(36)}$.
The association between tooth wear and age has been reported in several studies ${ }^{(11,12,35,37)}$ and our results confirmed this association in both dentitions. However, in the present study, the analysis showed new evidence: the association of tooth wear and BMI for primary teeth $(P=0.028)$. The health care of the child is the subject of many public health programmes worldwide. Our results showed an association of the nutritional status of children with tooth wear. In addition to the healthy growth of children, oral health care, especially tooth wear, is an irreversible loss of tissue and should be considered by oral health teams for improving public programmes focused on systemic oral health for children. However, it must be considered that a limitation of our study is its crosssectional design, making it difficult to draw the relationship regarding causes and effects. Therefore, further longitudinal studies are needed to better understand and interpret the tooth wear measures and associated risk factors in children.

A possible limitation of our study is the absence of dietary records for the children. The recall of eating habits could provide additional data on risk factors for tooth wear (dental erosion) to supplement the BMI. However, the large number of research subjects, as well as the need for participation of the children's parents in answering the questionnaire, made its analysis infeasible to be performed in the present study.

Quality of life, reported by the Child-OIDP, had no association with the oral conditions of children evaluated in the present study, as previously described by VargasFerreira et $a l .{ }^{(38)}$. The Child-OIDP focuses on measuring the ultimate impacts of disabilities and handicaps, capturing more proximal and intermediate impacts such as pain, discomfort, functional limitation and dissatisfaction with appearance ${ }^{(39)}$. The consequences of tooth wear are variable according to the literature. It has been suggested that tooth wear could affect the masticatory capacity and phonetics ${ }^{(40)}$, causing discomfort and pain symptoms ${ }^{(41,42)}$, dental sensitivity, enamel fracture and altered aesthetics $^{(43)}$ that could affect the self-rating of oral health, perceived needs and quality of life. However, the majority of studies have reported a low-severity grade of tooth erosion in children ${ }^{(43,44-47)}$. It was found that low levels of severity probably did not cause pain or any other psychosocial discomfort for the children in the present study. 


\section{Conclusions}

The present data suggest that there is an association between children's nutritional status and the severity of tooth wear. Underweight children had greater severity of tooth wear in the primary teeth and overweight/obese children had more severe lesions in the permanent teeth.

\section{Acknowledgements}

Acknowledgements: The authors acknowledge the valuable collaboration of all directors, teachers and schoolchildren involved in this investigation. Financial support: This research received no specific grant from any funding agency in the public, commercial or not-for-profit sectors. Conflict of interest: None. Authorship: P.G.M.-G. and A.S.-P. conceived the study design; A.C.S.-P. and M.A.A.M. collected the data; F.J.P.A. and S.H.C.S.-P. performed the analysis and wrote the manuscript. All authors approved the final version. Ethics of buman subject participation: The Research Ethics Committee of the Bauru School of Dentistry of the University of São Paulo approved this study. Positive consent was obtained from the participants' legal guardians on the day of the clinical examination. The study was conducted in full accordance with the World Medical Association Declaration of Helsinki.

\section{References}

1. Doak C, Monteiro C, Adai LS et al. (2000) Coexisting overweight and underweight within households is related to the nutrition transition. FASEB J 14, A792.

2. Doak CM, Adair LS, Bentley M et al. (2005) The dual burden household and the nutrition transition paradox. Int $J$ Obes (Lond) 29, 129-136.

3. Wells JCK (2012) Obesity as malnutrition: the role of capitalism in the obesity global epidemic. Am J Hum Biol 24, 261-276.

4. Popkin BM (1998) The nutrition transition and its health implication in lower-income countries. Public Health Nutr 1, Suppl. 1, 5-21.

5. Nascimento VG, Silva JPC, Bertoli CJ et al. (2012) Prevalence of overweight preschool children in public day care centers: a cross-sectional study. Sao Paulo Med J 130, Suppl. 4, 225-229.

6. Ohsuka K, Chino N, Nakagaki H et al. (2009) Analysis of risk factors for dental caries in infants: a comparison between urban and rural areas. Environ Health Prev Med 14, 103-110.

7. Oliveira LB, Sheiham A \& Bönecker M (2008) Exploring the association of dental caries with social factors and nutritional status in Brazilian preschool children. Eur J Oral Sci 116, 37-43.

8. Neves BG, Farah A, Lucas E et al. (2010) Are paediatric medicines risk factors for dental caries and dental erosion? Community Dent Health 27, Suppl. 1, 46-51.

9. Nunn J, Shaw L \& Smith A (1996) Tooth wear: dental erosion. Br Dent J 180, 349-352.

10. Addy M \& Shellis RP (2006) Interaction between attrition, abrasion and erosion in tooth wear. Monogr Oral Sci 20, 17-31.
11. Ratnayake N \& Ekanayake L (2010) Risk indicators for tooth wear in Sri Lankan adolescents. Caries Res 44, 14-19.

12. Sales-Peres SHC, Sales-Peres AC, Marsicano JA et al. (2013) An epidemiological scoring system for tooth wear and dental erosive wear. Int Dent J 63, 154-160.

13. Lussi A, Hellwig E, Zero DT et al. (2006) Erosive tooth wear: diagnosis, risk factors and prevention. Am J Dent 19 , 319-325.

14. Cunha-Cruz J, Pashova H, Packard JD et al. (2010) Tooth wear: prevalence and associated factors in general practice patients. Community Dent Oral Epidemiol 38, 228-234.

15. Lee A, He LH, Lyons K et al. (2012) Tooth wear and wear investigations in dentistry. J Oral Rehabil 39, 217-225.

16. Luo Y, Zeng XJ, Du MQ et al. (2005) The prevalence of dental erosion in preschool children in China. J Dent 33, 115-121.

17. McGrath C, Broder H \& Wilson-Genderson M (2004) Assessing the impact of oral health on the life quality of children: implications for research and practice. Community Dent Oral Epidemiol 32, 81-85.

18. Barbosa TS \& Gavião MBD (2008) Oral health-related quality of life in children. Part I: how well do children know themselves? A systematic review. Int J Dent Hygiene 6, 93-99.

19. Schlueter N \& Tveit AB (2014) Prevalence of erosive tooth wear in risk groups. Monogr Oral Sci 25, 74-98.

20. Bartlett DW, Lussi A, West N et al. (2013) Prevalence of tooth wear on buccal and lingual surfaces and possible risk factors in young European adults. J Dent 41, 1007-1013.

21. Sales-Peres SHC, Goya S, Araujo JJ et al. (2008) Prevalence of dental wear among 12-year-old Brazilian adolescents using a modification of the tooth wear index. Public Health 122, 942-948.

22. Instituto Brasileiro de Geografia e Estatística (2010) Características da População e Domicílios - Resultados do Universo - Notas Metodológicas. Rio de Janeiro: IBGE.

23. World Health Organization (2010) Handbook for Guideline Development. www.who.int/hiv/topics/mtct/grc_hand book_mar2010_1.pdf (accessed December 2014).

24. WHO Multicentre Growth Reference Study (2006) WHO Child Growth Standards: Length/Height-for-Age, Weight-for-Age, Weight-for-Length, Weight for-Height and Body Mass Index-forAge: Methods and Development. Geneva: WHO.

25. Castro RA, Cortes MI, Leao AT et al. (2008) Child-OIDP index in Brazil: cross-cultural adaptation and validation. Health Qual Life Outcomes 6, 68.

26. Pereira AJ, Rondo PHC, Lemos JO et al. (2013) Nutritional status and lipid profile of young children in Brazil. $J$ Trop Pediatr 59, Suppl. 1, 54-58.

27. Ferreira D \& Luciano SC (2010) Prevalence of extreme anthropometric measurements in children from Alagoas, Northeastern Brazil. Rev Saude Publica 44, 377-380.

28. Ogden CL, Carroll MD \& Flegal KM (2008) High body mass index for age among US children and adolescents, 2003-2006. JAMA 299, 2401-2405.

29. Gerber ZR \& Zielinsky P (1997) Fatores de risco de aterosclerose na infância: um estudo epidemiológico. Arq Bras Cardiol 69, 231-236.

30. Thompson JW \& Card-Higginson P (2009) Arkansas' experience: statewide surveillance and parental information on the child obesity epidemic. Pediatrics 124, Suppl. 1, 73-82.

31. McGuire J, Szabo A, Jackson S et al. (2009) Erosive tooth wear among children in the United States: relationship to race/ethnicity and obesity. Int J Paediatr Dent 19, 91-98.

32. Murakami C, Oliveira LB, Sheiham A et al. (2011) Risk indicators for erosive tooth wear in Brazilian preschool children. Caries Res 45, 121-129.

33. Lingstrom P \& Moynihan P (2003) Nutrition, saliva, and oral health. Nutrition 19,6. 
34. Ganss C, Klimek J \& Giese K (2001) Dental erosion in children and adolescents - a cross-sectional and longitudinal investigation using study models. Community Dent Oral Epidemiol 29, 264-271.

35. Sales-Peres SHC, Sales-Peres AC, Marsicano JA et al. (2011) The relationship between tooth wear in the primary and permanent dentitions. Community Dent Health 28 , 196-200.

36. Gambon DL, Brand HS \& Veerman ECI (2012) Dental erosion in the 21st century: what is happening to nutritional habits and lifestyle in our society? Br Dent J 213, 55-57.

37. Bardsley PF, Taylor S \& Milosevic A (2004) Epidemiological studies of tooth wear and dental erosion in 14-year-old children in North West England. Part 1. The relationship between water fluoridation and social deprivation. Br DentJ 197, 413-416.

38. Vargas-Ferreira F, Piosevan C, Praetzel JR et al. (2010) Tooth erosion with low severity does not impact child oral health-related quality of life. Caries Res 44, 531-539.

39. Nurelhuda NM, Ahmed MF, Trovik TA et al. (2010) Evaluation of oral health-related quality of life among Sudanese schoolchildren using Child-OIDP inventory. Health Qual Life Outcomes 8, 152.

40. Wiegand A, Müller J, Werner C et al. (2006) Prevalence of erosive tooth wear and associated risk factors in 2- to 7-year-old German kindergarten children. Oral Dis 12, $117-124$.

41. Williams D, Croucher R, Marcenes W et al. (1999) The prevalence of dental erosion in the maxillary incisors of 14-year-old schoolchildren living in Tower Hamlets and Hackney, UK. Int Dent J 49, 211-216.

42. Sivasithamparam K, Harbrow D, Vinczer E et al. (2003) Endodontic sequelae of dental erosion. Aust Dent $J \mathbf{4 8}$, 97-101.

43. Kazoullis S, Seow WK, Holcombe T et al. (2007) Common dental conditions associated with dental erosion in schoolchildren in Australia. Pediatr Dent 29, 33-39.

44. Peres KG, Armênio MF, Peres MA et al. (2005) Dental erosion in 12-year-old schoolchildren: a cross-sectional study in Southern Brazil. Int J Paediatr Dent 15, 249-255.

45. Auad SM, Waterhouse JHN, Steen N et al. (2007) Dental erosion amongst 13- and 14-year-old Brazilian schoolchildren. Int Dent J 57, 161-167.

46. Correr GM, Alonso RCB, Correa MA et al. (2009) Influence of diet and salivary characteristics on the prevalence of dental erosion among 12-year-old schoolchildren. $J$ Dent Child 76, 181-187.

47. Mangueira DF, Sampaio FC \& Oliveira AF (2009) Association between socioeconomic factors and dental erosion in Brazilian schoolchildren. J Public Health Dent 69, 254-259. 